\title{
Validation of a short and generic qualitative job insecurity scale (QUAL-JIS)
}

Gabriel Fischmann 1,2, http://orcid.org/0000-0002-2241-2423, gabriel.fischmann@student.kuleuven.be

Hans De Witte ${ }^{1,3}$, http://orcid.org/0000-0002-6691-517X, hans.dewitte@kuleuven.be

Coralia Sulea ${ }^{2,1}$, http://orcid.org/0000-0002-3209-6946, coralia.sulea@e-uvt.ro

Tinne Vander Elst ${ }^{1,4,5}$, http://orcid.org/0000-0001-8709-2371, tinne.vanderelst@idewe.be

Nele De Cuyper ${ }^{1}$, https://orcid.org/0000-0001-7241-9941, nele.decuyper@kuleuven.be

Dragos Iliescu ${ }^{6}$, http://orcid.org/0000-0002-5958-3920, dragos.iliescu@fpse.unibuc.ro

${ }^{1}$ WOPP-O2L, KU Leuven, Leuven, Belgium

${ }^{2}$ Department of Psychology, West University of Timisoara, Timisoara, Romania

${ }^{3}$ Optentia Research Focus Area, Vanderbijlpark Campus, North-West University, South Africa

${ }^{4}$ Knowledge, Information and Research Center, IDEWE Group, Leuven, Belgium

${ }^{5}$ Research Group of Work and Organizational Psychology, Vrije Universiteit

Brussel, Brussels, Belgium

${ }^{6}$ Department of Psychology, University of Bucharest, Bucharest, Romania

All correspondence, including proofs, should be sent to Gabriel Fischmann

(gabriel.fischmann@student.kuleuven.be), Research Group Work, Organisational \& Personnel Psychology WOPP - O2L, Faculty of Psychology \& Educational Sciences - KU Leuven, Van den Heuvelinstituut (VHI), Dekenstraat 2 (Postbox 3725), BE-3000 Leuven, Belgium. 


\begin{abstract}
The Qualitative Job Insecurity Scale (QUAL-JIS) has been used in job insecurity (JI) research for the past nine years, without undergoing a formal validation process. The goal of the current study was to test the scale's psychometric properties. We checked the scale's reliability, as well as its validity, investigating evidence based on the scale's content, internal structure, and relations to other variables (convergent and discriminant, predictive and concurrent, as well as incremental predictive evidence). We additionally evaluated its crosscountry and longitudinal invariance over three measurement times (six months apart) in two countries (Romania and Belgium; $N_{R O}=388, N_{B E}=1992$ ). We found evidence for the scale's reliability and validity, QUAL-JIS showing partial scalar invariance across time and between the two countries. Interestingly, qualitative JI measured with QUAL-JIS explained additional variance in the employees' need for recovery above and beyond another popular qualitative JI scale.
\end{abstract}

Keywords: qualitative job insecurity, scale validation, longitudinal, cross-country. 


\section{Introduction}

Job insecurity (JI), a "sense of powerlessness to maintain desired continuity in a threatened job situation" (Greenhalgh \& Rosenblatt, 1984, p. 438), is currently one of the most prevalent workplace stressors (Lee et al., 2018). Research consistently found JI to be harmful both for organizations and their employees (Shoss, 2017), with a recent metaanalysis (Sverke et al., 2019) concluding that JI is negatively associated with multiple types of impaired employee performance, and numerous studies providing evidence for the detrimental effect of JI on the employees' well-being, including their mental and physical health (De Witte et al., 2016; Sverke et al., 2002).

JI was initially conceptualized with two main components: the concern about losing the current job, and the perceived threat of losing valued job features (Greenhalgh \& Rosenblatt, 1984), coined quantitative and qualitative job insecurity respectively (Hellgren et al., 1999). Quantitative JI has attracted most attention, but qualitative JI research is quickly accumulating. Research (e.g., Fischmann et al., 2015; Gallie et al., 2017; Hellgren et al., 1999; Niesen et al., 2018) has identified both similar and different correlates for quantitative and qualitative JI, further emphasizing the need to distinguish between the two.

Given the increased attention for qualitative JI, our aim is to validate the QUAL-JIS scale. This scale has been used in at least six countries (e.g., Fischmann et al., 2018; Garrido Vásquez et al., 2017; Niesen et al., 2018; Roll et al., 2019; Urbanaviciute et al., 2018; Virga, 2015), yet to date without formal validation. The QUAL-JIS has a couple of unique features compared to other existing qualitative JI measures. First, the QUAL-JIS is relatively short (only four items) and shorter than the scales developed by Ashford et al. (1989), Lee et al. (2008), or O'Neill and Sevastos (2013). This is an advantage when the aim is to easily integrate the scale in more complex study questionnaires, where the total number of items is a deciding factor. Second, the QUAL-JIS is generic, unlike most measurements of qualitative JI, including Blotenberg and Richter (2020), Brondino et al. (2020), Burr et al. (2019), or 
Hellgren et al. (1999). Designing scales for a specific organizational context, targeting a number of specific job features, may be preferred in some cases. However, QUAL-JIS was meant to cover all possible features, with its generic items. We propose that the QUAL-JIS's briefness and genericity could make it an ideal instrument to measure qualitative JI in most circumstances.

Our goal in the current article is to describe the QUAL-JIS scale, to check if it is reliable and valid, and to consider whether scholars can confidently use it to measure qualitative JI. We will start by describing qualitative JI and explaining how the QUAL-JIS scale fits the construct. We continue with analyses of the scale's reliability and validity and conclude with recommendations for its future usage.

\section{Qualitative JI: construct and measures}

In their conceptual paper, Greenhalgh and Rosenblatt (1984) defined qualitative JI as the perceived threat of losing job features while keeping the current job. They also suggested a list of job features deemed to be principally associated with qualitative JI, like career progress, income stream, or autonomy.

The outcome of this conceptualization was the scale developed by Ashford et al. (1989): a 57-items measure, which covered both quantitative and qualitative JI. The Ashford et al. (1989) scale is arguably the most complete JI measurement tool in use today, yet it comes with some limitations. First, the measure is demanding for respondents and timeconsuming. The result is that it is not often used in studies, due to concerns about questionnaire length. Second, the scale covers many but not all possible valued job features, and some features that appear important in today's working life are missing. Examples of some lacking aspects are the opportunity to grow professionally (develop new skills, or enhance existing ones), a healthy work environment (including respect among colleagues, helping behaviours within the team, and lack of mistreatment behaviours), the presence of a mentor, the ability to work remotely when needed, or paid time off to take care of children. 
As such, the scale's ability to offer a comprehensive overview regarding a person's qualitative JI may have decreased during the last three decades, given the everchanging job types, work environments and employee work-related expectations.

Only the first limitation of the Ashford et al. (1989) scale has been addressed in more recent versions of the scale (abridged and bare-bones, see Lee et al., 2008) and with the introduction of other shorter qualitative JI measures on specific characteristics of work. For example, the scale developed by Hellgren et al. (1999), one of the most popular JI instruments to date, addressed the issue of scale complexity by reducing the number of job features to four. This selection was fitted to the specific organizational context in the study. Yet, specific items which are relevant in one context should not automatically be assumed to be reflecting qualitative JI in other settings. Other scales used in the qualitative JI literature (e.g., Chirumbolo \& Areni, 2010; Kalyal \& Sverke, 2010; Låstad et al., 2015), are based on Hellgren et al. (1999), having one item added or removed. As such, they retain the same merits and disadvantages as the original scale.

Other examples are two recently published qualitative JI scales, namely the Multidimensional Qualitative Job Insecurity Scale (MQJIS), validated by Brondino et al. (2020), and the Qualitative Job Insecurity Measure (QJIM), validated by Blotenberg and Richter (2020). MQJIS and QJIM are arguably upgrades compared to the Hellgren et al. (1999) scale, given the assessment of potentially twice respectively three times as many job features. However, the underlying issue of item specificity remains the same: measurements such as MQJIS and QJIM may be ideal in certain organizational settings, where there is a need to identify the more prominent aspects of qualitative JI, while a generic scale could be used initially to assess the extent to which employees feel insecure.

The O’Neill and Sevastos (2013) Multidimensional Job Insecurity Measure (JIM) includes a six items subscale which measures "job changes insecurity", a replacement term 
the authors used instead of qualitative JI. In addition to three generic formulated items, this scale also includes three items covering specific aspects of the work situation. This still implies that the experience measured by the JIM may not be equally applicable to all employees, as the selection of specific aspects that might be threatened could be relevant to some employees but not to others. Moreover, the authors' decision to use a new name for the construct instead of "qualitative JI" may have inadvertently obscured this scale from other JI researchers, resulting in a very low adoption rate by the JI research community. The COPSOQ Insecurity over Working Conditions scale (Burr et al., 2019) is very similar to JIM, insofar as it contains a combination of one generic and four specific items. It also offers a medium (three items) and a core (one item) version, both listing only specific job features.

Hence, the second limitation of the Ashford et al. scale (1989), namely that most instruments are measuring specific characteristics of work, implying the risk that important facets are missing, remains an issue of concern also in these shorter instruments. A possible solution would be to use a small number of items, tailor-fitted to each situation (as was the case in the Hellgren et al., 1999 study). This, however, raises a series of methodological problems. First, it is impractical to validate a new instrument for each usage. Second, an instrument created for one context may be wrongly reused in a different one. Last, the generality aspect is of the utmost importance for the instrument's ability to measure the intended construct: no matter how many specific job features are listed in a scale, there can never be any certainty that one covers all (or most) of the aspects valued by an employee in a particular context, or over time. For the reasons above, we argue for the need for a short generic qualitative JI scale, usable in any context. In the following section, we describe the QUAL-JIS scale and show that it overcomes all the issues listed above.

\section{The QUAL-JIS scale}

The QUAL-JIS scale is a four-item measure, developed by Hans De Witte and Nele De Cuyper in 2011, in response to the need for a short and generic scale. A panel of twelve 
experts, $\mathrm{PhD}$ students and professors in work and organizational psychology, was consulted by the authors, during a seminar organized for this purpose, to confirm the items' coverage of the qualitative JI construct. They addressed issues regarding the correct operationalization of the construct, to ensure both a close match between the items and the construct, and a high degree of item clarity, resulting in the final form of each item. As a next step, a check was performed on a group of non-experts, to verify if their understanding of the items was appropriate, and that the given answers were in line with what the authors expected. This convenience sample comprised of eighteen working respondents was asked to fill in the questionnaire, to assess each item's clarity in meaning, and to detail any problematic aspects, in their view. Although used in several studies in at least six countries (i.e., Belgium, China, Germany, Lithuania, the Netherlands, and Romania), no formal validation of this scale has been performed thus far. The QUAL-JIS scale was proposed as a counterpart of an already popular four-item quantitative JI scale, developed by De Witte (2000), and validated by Vander Elst et al. (2014).

In Table 1, we list the items in English, while the Dutch and Romanian versions, used in this study, are listed in Fischmann et al. (2021). By inspecting the items, it becomes apparent that the QUAL-JIS scale differs from other qualitative JI instruments by the fact that it instructs the respondent to state how much they agree with four generic items, rather than listing specific job features. The respondents are thus allowed to refer to any of their job characteristics and are not restricted to a predefined set. Consequently, we conclude that the QUAL-JIS scale was not affected by the item specificity issue, being generic and as such usable in a wider variety of contexts compared to other scales.

The formulation of generic statements allowed for a significantly smaller number of items. With only four items, the QUAL-JIS scale can be included in most questionnaires without too large of an overhead. 
Table 1

Items of the QUAL-JIS scale

\section{English version}

Instructions for the respondent: To what extent do you agree with the following statements?

Response options: 1) Completely disagree; 2) Disagree; 3) Partially agree, partly disagree; 4) Agree; 5) Completely agree

Item 1: I think that my job will change for the worse in the near future.

Item 2: I feel insecure about the characteristics and conditions of my job in the future.

Item 3: I am worried about what my job will look like in the future.

Item 4: Chances are, my job will change in a negative way.

\section{The current study}

Research already provided validity evidence for QUAL-JIS, in the form of associations with known outcomes of qualitative JI, such as employee well-being (Nikolova et al., 2019; Roll et al., 2019; Urbanaviciute et al., 2020; Van den Broeck et al., 2019), physical and mental health (Iliescu et al., 2017), various types of performance (in-role: Fischmann et al., 2018; extra-role: Van den Broeck et al., 2014; idea generation: Niesen et al., 2018; innovative work behaviour: Roll et al., 2015; learning: Van Hootegem \& De Witte, 2019), and turnover intent (Urbanaviciute et al., 2018).

The current study's purpose is to build on previous findings and further assess whether the QUAL-JIS scale is reliable, valid, and invariant across time and between countries. 


\section{Reliability}

We assessed the scale's reliability by means of an internal consistency indicator, Cronbach's alpha coefficient. Although there is no definite statistical criterion regarding the recommended threshold for the alpha coefficient, values between .70 and .95 are generally reported as acceptable (Tavakol \& Dennick, 2011), values larger than .80 show very good reliability, and extremely high values possibly (but not necessarily) indicate redundancy among items (Hulin et al., 2001). We thus formulate:

H1. The QUAL-JIS scale is reliable.

Validity

We investigated QUAL-JIS's validity by assessing a number of aspects: whether the instrument covers the complete scope of the construct, if the theoretical construct of qualitative JI is operationalized correctly and thus QUAL-JIS is measuring the right construct, and if measuring qualitative JI with QUAL-JIS results in expected relations with some known outcomes.

Distinctiveness from Quantitative JI. As an initial step to verify the constructrelated aspect of validity, we need to be able to discern between the two facets of JI, quantitative and qualitative. Research already established that the two types of JI, although sharing several predictors and outcomes, are distinct constructs, relating differently to outcomes such as employee performance and well-being (De Witte et al., 2010; Fischmann et al., 2015; Gallie et al., 2017; Hellgren et al., 1999). The two should thus appear distinct from one another in a confirmatory factor analysis (CFA). We thus formulate:

H2. Qualitative JI measured with the QUAL-JIS scale is distinct from quantitative JI. Contrary to the first two hypotheses, which use country data independently, the next validity-related hypotheses are tested with models using cross-county data. As such, as a next step, we investigate the cross-country invariance, before continuing with further validity checks. 
Cross-Country Invariance. We collected data from two countries, Belgium and Romania. Including both countries is of interest given that they differ on structural aspects, economic conditions and cultural dimensions (Hofstede, 2011). For a brief structural, economic, and cultural comparison of the two countries, see Fischmann at al. (2021).

To be able to compare means across countries, QUAL-JIS must display scalar invariance. We must thus evaluate three levels of invariance: configural invariance (i.e., the model holds for both counties), metric invariance (i.e., besides configural invariance, the factor loadings are the same across measurements), and scalar invariance (i.e., besides metric invariance, the intercepts are invariant between measurements). Configural invariance means that the assignment of scale item scores onto the latent factor produces a model with a good fit for both countries. Metric invariance shows that each item contributes to the latent construct in the same way in Belgium, as in Romania. If the two translations of the scale are scalar invariant, then raw scores (and, by consequence, means) obtained in these countries can be meaningfully compared. We hypothesize:

H3: The QUAL-JIS scale shows configural, metric, and scalar invariance between countries.

Convergent and discriminant evidence. Our study includes checks for two additional aspects of validity. We assess convergent evidence as the degree to which qualitative JI measured with the QUAL-JIS scale is related to quantitative JI, a construct known to be theoretically related to qualitative JI. Theoretical works (e.g., Greenhalgh \& Rosenblatt, 1984) as well as empirical studies (e.g., Fischmann et al., 2015) have shown the two types of JI to be related, though distinct. For discriminant evidence, we must determine that qualitative JI measured with the QUAL-JIS scale is not related to a dissimilar construct. Work engagement was theorized as the opposite of burnout (Schaufeli et al., 2002), as a state of mind characterized by vigour, dedication and absorption. Dedication is characterized by a 
strong involvement in one's work, accompanied by a sense of significance, enthusiasm, inspiration, pride, and challenge (Schaufeli \& Bakker, 2010). Since JI theory and work engagement theory define JI components and work engagement facets in completely different contexts as separate constructs, we expect that, e.g., qualitative JI is distinct from the work engagement facet of dedication. A correlation coefficient larger than .50 is indicative of a strong correlation (Cohen, 1988). Therefore, we hypothesize:

H4. Qualitative JI measured with the QUAL-JIS scale correlates strongly and positively with quantitative JI.

H5. Qualitative JI measured with the QUAL-JIS does not correlate strongly with dedication.

Test-criterion relationships. We verify two aspects of validity related to QUALJIS's ability to measure qualitative JI in relationship with one of its known outcomes: the predictive aspect (qualitative JI measured with QUAL-JIS predicts the criterion in a future time point) and the incremental one (the QUAL-JIS scale outperforms an alternative measure of qualitative JI in how much variability it explains in the outcome). We chose the need for recovery as the criterion variable. According to transactional stress theory (Lazarus \& Folkman, 1984), when people encounter a stressor (e.g., qualitative JI), they engage in a twoparts cognitive process: first the individuals evaluate what is at stake (e.g., the future characteristics of the job) and then they consider how they can handle it. The efforts invested in coping with stress may lead to fatigue and decreased energy, and, in turn, to increased need for recovery. As a preliminary test before checking the predictive aspect of validity, we need to verify that the QUAL-JIS scale is invariant across time. If QUAL-JIS displays scalar invariance across time, then the scores obtained by the participants would have the same meaning, being comparable to one another and, as such, could be used in across-time means comparisons. Consequently, we propose: 
H6: The QUAL-JIS scale shows configural, metric, and scalar invariance across time.

H7. Qualitative job insecurity measured with the QUAL-JIS scale predicts need for recovery over time.

Being generic, we expect the QUAL-JIS scale to be superior to existing non-generic scales in capturing the complete construct of qualitative JI. A generic scale should, by definition, cover the whole construct, while a scale measuring specific characteristics of work can only reflect part of it. As such, we hypothesize that QUAL-JIS would explain additional variance in the outcome, in an incremental manner, compared to another qualitative JI scale.

H8. The QUAL-JIS scale explains additional variance for the need for recovery, compared to a qualitative JI scale measuring specific characteristics of work.

\section{Method}

Procedure and participants

Our hypotheses were tested using a Romanian (Sample 1) and a Belgian sample (Sample 2). Specifically, hypotheses 1-7 were tested using both samples, while hypothesis 8 was tested using Sample 2, because qualitative JI measured with the Hellgren et al. (1999) scale was not included in the Romanian version of the questionnaire.

For Sample 1, we used a snowball procedure. Four trained interviewers commissioned from a survey company and supervised by a field supervisor collected the data, each in a different Romanian city. The contract with the survey company specified that we would receive data on 400 participants, three times, six months apart: May 2012 (T1-RO), November 2012 (T2-RO), and May 2013 (T3-RO). The entry procedure was based on the random selection of a household, out of the census list of households. One participant from the household filled out a self-administered paper-and-pencil questionnaire at home, which was then handed back to the interviewer. After completion of the questionnaire, each participant was asked to recommend at least one other person for participation, and these leads were followed up to a total of 400 respondents. To control for some of the limitations of 
the snowball procedure, each participant was asked to recommend other participants who are as different as possible from themselves regarding demographic characteristics such as age, gender, or occupation. The participants agreed to provide data three times, six months apart. They were also advised that participation was entirely voluntary, that they were free to refrain from answering questions, and that their responses would be treated as confidential at the individual level.

We removed the answers from four participants who did not provide complete answers for the study variables and eight participants who were self-employed, remaining with a sample size of $N 1=388$. The age of the participants at T1-RO varied between 19 and 65 years $(M=36.00 ; S D=9.94)$. More than half of the participants $(56 \%)$ were female. With regard to professional level, $2.6 \%$ of the respondents were unskilled blue-collar workers, 13.4\% were skilled blue-collar workers, $28.1 \%$ were lower-level white-collar workers (e.g., typist, secretary, operator), $24.5 \%$ were intermediate white-collar workers (e.g., programmer, instructor, representative), $24.7 \%$ were upper white-collar workers (e.g., administrator, engineer, teacher) and $6.2 \%$ held a managerial job. Most participants (94.3\%) worked under full-time contracts, and $92.3 \%$ were employed on a permanent base.

For Sample 2, data were collected among a heterogeneous group of employees in Flanders (Belgium) in April 2012 (T1-BE), November 2012 (T2-BE), and April 2013 (T3$\mathrm{BE})$, thus with a time lag of approximately six months between subsequent measurements. At T1-BE, readers of a Flemish human resources magazine were asked to participate in a largescale survey on the impact of insecure work on workers' functioning. We emphasized the voluntary participation and the confidential treatment of the study results. As the focus was on employees in the working-age (18-65 years), self-employed workers and individuals outside the 18-65 years age span were omitted from the sample. This selection resulted in a group of 3415 employees with complete answers at T1-BE. Most of these respondents 
provided a correct email address $(N=2223)$ and could be invited to the survey a second and a third time. At T2-BE, 957 individuals joined the study, and at T3-BE information was provided by 858 people. We removed all participants $(n=229)$ who became unemployed at T2-BE or T3-BE as well as respondents who changed jobs between the measurements, as job transitions may have influenced the lagged relationships. Therefore, a final sample of 1994 employees who participated in the survey at least once resulted (i.e., at T1-BE). We removed the answers for two participants since they did not provide complete answers for the study variables, remaining with a sample size of $N 2=1992$.

Sample 2 was a heterogeneous group of employees working in both the private (63.5\%) and the public sector (36.5\%) and in different types of branches (e.g., industry, retail, education, health care, IT). Respondents' mean age was 38.05 years $(S D=11.49)$, and the majority were female $(64.3 \%)$. Eleven percent were blue-collar workers, $65.6 \%$ were whitecollar workers, and $23.9 \%$ were managers (i.e., supervisors and members of the board). Most of the respondents $(88.1 \%)$ had a permanent contract, and many worked on a full-time basis $(77.1 \%)$.

Measures

All scale reliabilities are shown in the Results section, in Table 2 for the Belgian data and in Table 3 for the Romanian data.

Qualitative JI. In all samples, qualitative JI was measured with the QUAL-JIS scale, as described in Table 1. Additionally, we measured qualitative JI at T2-BE and T3-BE, with the Hellgren et al. (1999) scale. The items were rated on a 5-point Likert-type scale ( $1=$ "totally disagree"; 5 = "totally agree"). A sample item is "My pay development in this organization is promising" (reverse-scored item).

Quantitative JI. We measured quantitative JI, in both samples, with the four-item Job Insecurity Scale (JIS) developed by De Witte (2000) and validated by Vander Elst et al. 
(2014). The items were rated on a 5-point Likert-type scale ( 1 = "totally disagree"; 5 = "totally agree"). A sample item is "I think I might lose my job in the near future".

Dedication. We measured dedication with the three items from the short version of the Utrecht Work Engagement Scale (Schaufeli \& Bakker, 2010). The items were rated on a 6-point Likert-type scale ( 0 = "never"; 6 = "always/ every day"). A sample item is "I am enthusiastic about my job".

Need for recovery. We measured the employees' need for recovery with three items from the Short Inventory to Monitor Psychosocial Hazards (Notelaers et al., 2007). The items were rated on a 5-point Likert-type scale ( $1=$ "totally disagree"; $5=$ "totally agree"). A sample item is "I find it difficult to relax at the end of a working day".

\section{Analysis}

Our study has four main parts. First, we checked for scale reliability, by means of Cronbach's alpha, on all six sample-time point combinations. Second, we used data from T1 in both samples, to perform a CFA of the measurement model, to verify invariance across the two countries, and to test for convergent (with quantitative JI) and discriminant (against dedication) evidence of the QUAL-JIS scale. Third, we tested whether qualitative JI measured with QUAL-JIS predicted the need for recovery, in a longitudinal setting for each country. Last, we check for incremental predictive evidence of the QUAL-JIS scale in comparison with another well-known qualitative JI measure, on the Belgian sample, at T2 and T3.

We used structural equation modelling for our CFA and invariance analyses. We performed a CFA on the measurement model at $\mathrm{T} 1$, where we did not allow any measurement errors to covary, except for the ones associated with the first and third items of the quantitative JI scale (see Figure 1). Given the very similar wording of the two items, compared to the rest of the quantitative JI scale, it was not surprising that they shared some additional variance, besides that covered by the latent factor. As such, we decided to keep the 
inter-error correlation in the model. The model goodness-of-fit was evaluated by using absolute fit indices (the chi-square statistic, the standardized root mean squared residual, and the root mean square error of approximation) and relative fit indices (the non-normed fit index and the comparative fit index).

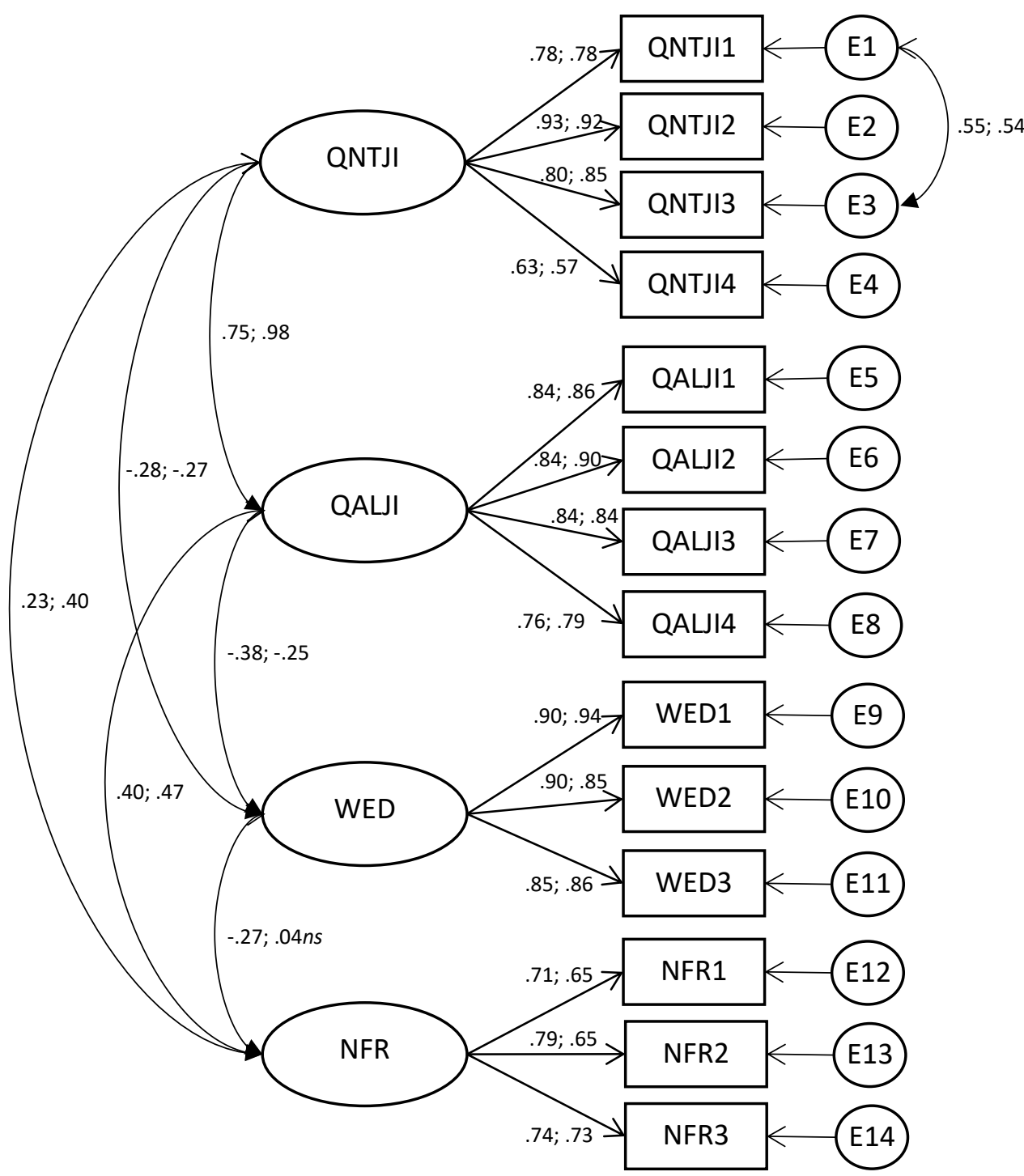

Figure 1 The four-factor models, M1 (BE sample) and M3 (RO sample). In each pair, the first value is from MI and the second one from M3. Standardized factor loadings and inter-factor correlations are displayed. No inter-error correlations were allowed, except for E1-E3. $Q N T J I=$ quantitative job insecurity; $Q A L J I-$ qualitative job insecurity; $W E D=$ work engagement dedication; $N F R=$ need for recovery.

Values smaller than .06 for RMSEA and .08 for SRMR, combined with values higher than .95 for NNFI and CFI are considered to indicate a good fit (Hu \& Bentler, 1999). We 
compared two theoretically possible models for each country (see Table 4), using the Chisquare difference test: M1 and M3 the four-factor CFA model (i.e., quantitative JI, qualitative JI, dedication and need for recovery), versus M2 and M4 a three-factor model where quantitative and qualitative JI loaded on the same factor.

We checked for measurement invariance between countries and for each country over time. We assessed configural invariance with multi-group CFA analyses by including all the compared groups simultaneously in the model. This resulted in three separate analyses: one between the two countries, at T1, a second one, between T1, T2, and T3 in the Belgian sample, and a third one, between T1, T2, and T3 in the Romanian sample. Good model fits indicate configural invariance. Each subsequent level of invariance (metric and scalar) is considered fulfilled if the respective model does not show a fit decrease compared with the configural invariance model (i.e., the baseline model, Schmitt \& Kuljanin, 2008). If RMSEA increases by at least .015 and CFI decreases by at least .01, we conclude that we have a significant decrease in model fit (Chen, 2007; Cheung \& Rensvold, 2002). If full scalar invariance is supported, one can confidently carry out comparisons of observed scores and means. Partial scalar invariance would indicate that in certain cases such comparisons may be allowed, while in other cases the non-equivalent items should be removed (for a detailed discussion see Putnick \& Bornstein, 2016).

Given the fact that QUAL-JIS is used mostly in organizational psychology research, and that the de facto standard for the usage of such a scale in this context is to calculate total scores either as a sum, or as an average of the individual observed item scores, we decided to use similar methods in our next validation steps. This way, our findings would be directly compatible with what other research already established, or will show, in the future. We performed validity checks for the QUAL-JIS scale by means of zero-order correlations and hierarchical linear regressions based on observed scores, to gather evidence regarding the 
relationships with other variables (converging with quantitative JI, discriminating against

dedication, predicting the need for recovery, and incrementally predicting the need for

recovery beyond another qualitative JI scale).

Structural equation modelling analyses were performed in IBM SPSS Amos 27, while

for all other analyses we used IBM SPSS Statistics 27.

Results

Reliability. Correlations, as well as means, standard deviations and scale reliabilities

are shown in Table 2 for the Belgian data and in Table 3 for the Romanian data.

Table 2

Correlations, reliabilities, means, and standard deviations in the Belgian sample

\begin{tabular}{|c|c|c|c|c|c|c|c|c|c|c|c|c|c|c|}
\hline Variables & $M$ & $S D$ & 1. & 2. & 3. & 4. & 5. & 6. & 7. & 8. & 9. & 10. & 11. & 12. \\
\hline 1. QUAL-JIS (T1) & 2.63 & .94 & $(.89)$ & & & & & & & & & & & \\
\hline 2. QUAL-JIS (T2) & 2.88 & .80 & .67 & $(.81)$ & & & & & & & & & & \\
\hline 3. QUAL-JIS (T3) & 2.93 & .79 & .60 & .72 & $(.82)$ & & & & & & & & & \\
\hline 4. Other qualitative JI (T2) & 3.05 & .68 & .38 & .59 & .50 & $(.70)$ & & & & & & & & \\
\hline 5. Other qualitative JI (T3) & 3.09 & .68 & .33 & .48 & .61 & .65 & (.69) & & & & & & & \\
\hline 6. Quantitative JI (T1) & 2.15 & .92 & .60 & .44 & .37 & .32 & .26 & $(.89)$ & & & & & & \\
\hline 7. Quantitative JI (T2) & 2.14 & .86 & .46 & .58 & .44 & .40 & .35 & .72 & (.89) & & & & & \\
\hline 8. Quantitative JI (T3) & 2.20 & .89 & .43 & .45 & .57 & .37 & .39 & .69 & .76 & $(.90)$ & & & & \\
\hline 9. Dedication (T1) & 4.06 & 1.38 & -.34 & -.35 & -.33 & -.37 & -.30 & -.23 & -.24 & -.24 & $(.92)$ & & & \\
\hline 10. Need for recovery $(\mathrm{T} 1)$ & 2.46 & .83 & .34 & .35 & .31 & .16 & .18 & .16 & .11 & .16 & -.22 & (.79) & & \\
\hline 11. Need for recovery (T2) & 2.43 & .90 & .34 & .35 & .31 & .20 & .23 & .13 & .11 & $.11 *$ & -.19 & .73 & $(.83)$ & \\
\hline 12. Need for recovery (T3) & 2.38 & .86 & .32 & .43 & .36 & .24 & .22 & .17 & .20 & .18 & -.17 & .67 & .74 & $(.80)$ \\
\hline
\end{tabular}

Note. $* p \leq .05$, all other correlations $p \leq .01$. Cases excluded pairwise, $N$ between 392 and 1992. Scale reliabilities on the diagonal. $\mathrm{T} 1=$ time one, $\mathrm{T} 2=$ time two $(\mathrm{T} 1+6$ months $), \mathrm{T} 3=$ time three $(\mathrm{T} 1+12$ months $)$. JI = job insecurity. QUAL-JIS = qualitative JI measured with the QUAL-JIS scale. Other qualitative JI = JI measured with the Hellgren et al. (1999) scale.

Table 3

Correlations, reliabilities, means, and standard deviations in the Romanian sample

\begin{tabular}{lllllllllllll}
\hline Variables & $M$ & $S D$ & 1. & 2. & 3. & 4. & 5. & 6. & 7. & 8. & 9. & 10. \\
\hline 1. QUAL-JIS (T1) & 2.00 & .83 & $(.91)$ & & & & & & & & & \\
2. QUAL-JIS (T2) & 1.97 & .66 & .57 & $(.81)$ & & & & & & & \\
3. QUAL-JIS (T3) & 1.96 & .62 & .49 & .59 & $(.82)$ & & & & & & \\
4. Quantitative JI (T1) & 2.01 & .80 & .84 & .55 & .43 & $(.87)$ & & & & & \\
5. Quantitative JI (T2) & 1.95 & .64 & .50 & .78 & .48 & .59 & $(.78)$ & & & & \\
6. Quantitative JI (T3) & 1.97 & .58 & .45 & .47 & .78 & .47 & .62 & $(.72)$ & & & \\
7. Dedication (T1) & 3.75 & 1.58 & -.24 & -.30 & -.16 & -.28 & -.26 & -.17 & $(.91)$ & & \\
8. Need for recovery (T1) & 2.39 & .84 & .38 & .23 & .20 & .28 & .22 & .18 & $.04 n s$ & $(.72)$ & & \\
9. Need for recovery (T2) & 2.52 & .85 & .35 & .29 & .22 & .32 & .28 & .22 & $-.01 n s$ & .69 & $(.72)$ & \\
10. Need for recovery (T3) & 2.69 & .92 & .35 & .35 & .17 & .32 & .33 & .16 & $-.03 n s$ & .62 & .80 & $(.73)$ \\
\hline
\end{tabular}

Note. $n s=p>.05$, all other correlations $p \leq .01 . N=388$. Scale reliabilities on the diagonal. $\mathrm{T} 1=$ time one, $\mathrm{T} 2=$ time two (T1+6 months), T3 = time three (T1+12 months). JI = job insecurity. QUAL-JIS = qualitative JI measured with the QUAL-JIS scale. 
The QUAL-JIS scale was found to be reliable, with high Cronbach's alpha values across countries and time: $\alpha(\mathrm{T} 1-\mathrm{BE})=.89, \alpha(\mathrm{T} 2-\mathrm{BE})=.81, \alpha(\mathrm{T} 3-\mathrm{BE})=.82, \alpha(\mathrm{T} 1-\mathrm{RO})=.91$, $\alpha(\mathrm{T} 2-\mathrm{RO})=.81$, and $\alpha(\mathrm{T} 3-\mathrm{RO})=.82$. As such, $\mathrm{H} 1$ is supported by our findings.

Distinctiveness from quantitative JI. To assess whether qualitative JI, quantitative JI, dedication and need for recovery could be used as separate variables, we performed three CFAs on nested models for each sample, comparing a model with all four variables (M1 in BE sample, M3 in RO sample) to one in which quantitative and qualitative JI were modelled into a single variable (M2 in BE sample, M4 in RO sample). Results (see Table 4) indicated that the four-factor model was the best fitting model in both samples, with indices showing a good model fit for the Belgian $(\mathrm{CFI}=.974, \mathrm{NNFI}=.966, \mathrm{RMSEA}=.058$, and $\mathrm{SRMR}=$ $.038)$ and the Romanian $(\mathrm{CFI}=.962, \mathrm{NNFI}=.951, \mathrm{RMSEA}=.074$, and $\mathrm{SRMR}=.043)$ data. M2 and M4 displayed significantly worse fit indices and did not show a consistently acceptable fit between the two data sets. The fact that M1 and M3 outperformed M2 and M4 supports our hypothesis $\mathrm{H} 2$ that quantitative and qualitative JI are distinct from one another.

Table 4

Fit indices for CFA analyses

\begin{tabular}{ccccccccccc}
\hline Model & $\chi 2$ & $\mathrm{df}$ & $\chi 2 / \mathrm{df}$ & CFI & NNFI & SRMR & RMSEA & $\Delta \chi^{2}$ & $\Delta$ df & $\mathrm{p}$ \\
\hline Measurement models Belgium at T1 & & & & & & & & & & \\
M1 four-factor model & 532.270 & 70 & 7.604 & .974 & .966 & .038 & .058 & & \\
M2 three-factor model & 1720.485 & 74 & 23.250 & .906 & .885 & .068 & .106 & 1188.22 & 4 & $<.001$ \\
Measurement models Romania at T1 & & & & & & & & & & \\
M3 four-factor model & 217.261 & 70 & 3.104 & .962 & .951 & .043 & .074 & & \\
M4 three-factor model & 235.185 & 74 & 3.178 & .959 & .949 & .046 & .075 & 17.924 & 4 & .001 \\
\hline
\end{tabular}

Invariance between countries. We performed multi-group cross-country invariance checks at T1 (see Table 5). In the configural invariance model we fixed the factor loading of the first item for each time slot to 1 and its item intercept to 0 . In the full metric invariance model, we constrained the factor loadings for each item to be equal across time. In the full 
scalar invariance model, we additionally constrained all item intercepts to be equal across time. In the partial scalar invariance model, we freely estimated up to half of the item intercepts in a stepwise procedure, to test for partial scalar invariance. We allowed the intercepts for items 2 and 4 to vary between groups, since their selection provided the best overall model fit indices. Results indicated that the QUAL-JIS scale displays configural (CFI $=.996$, RMSEA $=.045)$, full metric $(\mathrm{CFI}=.995, \mathrm{RMSEA}=.042)$ and partial scalar invariance $(\mathrm{CFI}=.994, \mathrm{RMSEA}=.040)$ between the Belgian and Romanian data. $\mathrm{H} 3$ was thus supported. As such, the scale meaning, measurement unit and origin seem to be similar, allowing for means and raw observed scores comparisons between the two countries.

Table 5

Multi-group cross-country invariance checks

\begin{tabular}{ccccccccccccc}
\hline \multicolumn{1}{c}{ Invariance type } & $\chi^{2}$ & $\mathrm{df}$ & $\chi^{2} / \mathrm{df}$ & CFI & NNFI & RMSEA & Delta & $\Delta$ CFI & $\Delta$ NNFI & $\Delta$ RMSEA \\
\hline M5 Configural invariance & 23.442 & 4 & 5.856 & .996 & .989 & 0.045 & & & \\
& & & & & & & & & \\
M6 Full metric invariance & 36.091 & 7 & 5.156 & .995 & .991 & 0.042 & M6-M5 & -.001 & .002 & -.003 \\
M7 Full scalar invariance & 141.888 & 10 & 14.189 & .976 & .971 & 0.074 & M7-M5 & -.020 & -.018 & .029 \\
M8 Partial scalar invariance & 38.361 & 8 & 4.795 & .994 & .992 & 0.040 & M8-M5 & -.002 & .003 & -.005 \\
\hline
\end{tabular}

Convergence evidence. Next, we measured the Pearson correlation between the qualitative and quantitative JI. Results were significant, positive, and of high strength in the Belgian and Romanian samples, $r_{\mathrm{T} 1-\mathrm{BE}}=.60, p<.001$ and $r_{\mathrm{T} 1-\mathrm{RO}}=.84, p<.001$, data supporting H4. Additionally, we calculated the inter-factor correlations in models M1 and M3 (see Figure 1). The high inter-factor correlations between quantitative and qualitative JI (.75 in the Belgian sample and .98 in the Romanian one) supported our hypothesis as well, while at the same time raising the potential issue of distinctiveness between quantitative and qualitative JI. We approached this issue in hypothesis $\mathrm{H} 2$ and we further discuss it in the Discussion section. 
Divergence evidence. The discriminant aspect of validity was assessed by means of the Pearson correlation between qualitative JI and dedication, corrected for attenuation due to measurement error: $r_{\mathrm{JI}-\mathrm{Ded}}^{*}=r_{\mathrm{JI}-\mathrm{Ded}} / \operatorname{sqrt}\left(r_{\mathrm{JI}-\mathrm{JI}} * r_{\text {Ded-Ded }}\right)$. A correlation lower in absolute value than .50 (i.e., not a strong correlation; Cohen, 1988) would be indicative of the fact that the two variables are distinct from one another. Results were $r^{*}$ T1-BE=-.38 and $r^{*}$ T1-RO=-.26. Given the medium-low corrected correlations, H5 is supported by the results.

Table 6

Within country invariance over time

\begin{tabular}{|c|c|c|c|c|c|c|c|c|c|c|}
\hline Model & $\chi^{2}$ & $\mathrm{df}$ & $\chi^{2} / \mathrm{df}$ & CFI & NNFI & RMSEA & Delta & $\Delta \mathrm{CFI}$ & $\Delta$ NNFI & $\triangle \mathrm{RMSEA}$ \\
\hline \multicolumn{11}{|l|}{ Belgian sample T1-T2-T3 } \\
\hline M9 Configural invariance & 68.260 & 39 & 1.750 & .996 & .992 & .019 & & & & \\
\hline M10 Full metric invariance & 471.749 & 45 & 10.483 & .944 & .903 & .069 & M10-M9 & -.052 & -.089 & .050 \\
\hline M11 Partial metric invariance & 73.185 & 41 & 1.785 & .996 & .992 & .020 & M11-M9 & .000 & .000 & .001 \\
\hline M12 Partial scalar invariance & 82.380 & 43 & 1.916 & .995 & .991 & .021 & M12-M9 & -.001 & -.001 & .002 \\
\hline \multicolumn{11}{|l|}{ Romanian sample T1-T2-T3 } \\
\hline M13 Configural invariance & 120.055 & 39 & 3.078 & .974 & .957 & .073 & & & & \\
\hline M14 Full metric invariance & 122.973 & 45 & 2.733 & .975 & .964 & .067 & M14-M13 & .001 & .007 & -.006 \\
\hline M15 Full scalar invariance & 173.363 & 51 & 3.399 & .961 & .950 & .079 & M15-M13 & -.013 & -.007 & .006 \\
\hline M16 Partial scalar invariance & 140.446 & 47 & 2.988 & .970 & .958 & .072 & M16-M13 & -.004 & .001 & -.001 \\
\hline
\end{tabular}

Invariance across time. Invariance checks across time (see Table 6) showed the QUAL-JIS scale as invariant. We compared multiple models of qualitative JI for each country, including all measurement times. We allowed for inter-error correlations for the same item across time. We found configural (M9), partial metric (M11), and partial scalar (M12) invariance (we freely estimated the factor loadings and the item intercepts for items 2 and 4) in the Belgian sample, and configural (M13), full metric (M14), and partial scalar (M16) invariance (we allowed the item intercepts for items 2 and 4 to vary across groups) in the Romanian sample. Results indicate good model fit in all six models, with CFI and RMSEA differences being lower than .01 between subsequent nested models and the 
configural invariance model, as needed to determine invariance. We thus found support for H6, allowing us to proceed with validity checks across time.

Test-criterion predictive evidence. We measured the predictive ability of qualitative JI measured with QUAL-JIS for need for recovery, with linear regressions of the dependent variable at $\mathrm{T}+1$ onto qualitative $\mathrm{JI}$ at time $\mathrm{T}$ (see Table 7 ). We expected past qualitative $\mathrm{JI}$ measured with QUAL-JIS to significantly relate to the future need for recovery, on both occasions. In the Belgian sample, qualitative JI at T1 predicted need for recovery at T2 with $\beta=.34, p<.001$, and qualitative $\mathrm{JI}$ at T2 predicted need for recovery at T3 with $\beta=.43, p<.001$.

Table 7

Predictive and concurrent validity checks through hierarchical linear regression analyses

\begin{tabular}{|c|c|c|c|c|c|c|c|c|c|c|c|c|c|c|c|c|}
\hline \multirow{4}{*}{$\begin{array}{l}\text { Sample } \\
\text { Outcome } \\
\text { JI order } \\
\text { Step }\end{array}$} & \multicolumn{8}{|c|}{ Belgian sample } & \multicolumn{8}{|c|}{ Romanian sample } \\
\hline & \multicolumn{4}{|c|}{ Need for recovery at $\mathrm{T} 2$} & \multicolumn{4}{|c|}{ Need for recovery at $\mathrm{T} 3$} & \multicolumn{4}{|c|}{ Need for recovery at $\mathrm{T} 2$} & \multicolumn{4}{|c|}{ Need for recovery at $\mathrm{T} 3$} \\
\hline & \multicolumn{2}{|c|}{ T1 first } & \multicolumn{2}{|c|}{ T2 first } & \multicolumn{2}{|c|}{ T2 first } & \multicolumn{2}{|c|}{ T3 first } & \multicolumn{2}{|c|}{ T1 first } & \multicolumn{2}{|c|}{ T2 first } & \multicolumn{2}{|c|}{ T2 first } & \multicolumn{2}{|c|}{ T3 first } \\
\hline & 1 & 2 & 1 & 2 & 1 & 2 & 1 & 2 & 1 & 2 & 1 & 2 & 1 & 2 & 1 & 2 \\
\hline$\beta \mathrm{JI}$ at $\mathrm{T} 1$ & $.34^{* * * *}$ & $.18^{* * *}$ & & $.18^{* * *}$ & & & & & $.35^{* * *}$ & $.28^{* * *}$ & & $.28^{* * * *}$ & & & & \\
\hline$\beta \mathrm{JI}$ at $\mathrm{T} 2$ & & $.23^{* * *}$ & $.35^{* * *}$ & $.23^{* * *}$ & $.43^{* * *}$ & $.31^{* * *}$ & & $.31^{* * *}$ & & $.13^{*}$ & $.29^{* * *}$ & $.13^{*}$ & $.35^{* * *}$ & $.39^{* * *}$ & & $.39^{* * * *}$ \\
\hline$\beta \mathrm{JI}$ at $\mathrm{T} 3$ & & & & & & $.18^{* *}$ & $.40^{* * *}$ & $.18^{* *}$ & & & & & & -.06 & $.17^{* *}$ & -.06 \\
\hline Adj. $R^{2}$ & .11 & .14 & .12 & .14 & .19 & .20 & .16 & .20 & .12 & .13 & .08 & .13 & .12 & .12 & .03 & .12 \\
\hline$\Delta R^{2}$ & $.11^{* * * *}$ & $.03^{* * * *}$ & $.12^{* * * *}$ & $.02^{* * *}$ & $.19^{* * *}$ & $.02^{* *}$ & $.16^{* * *}$ & $.05^{* * *}$ & $.12^{* * *}$ & $.01^{*}$ & $.08^{* * *}$ & $.05^{* * *}$ & $.12^{* * *}$ & $<.01$ & $.03^{* *}$ & $.10^{* * * *}$ \\
\hline
\end{tabular}

Note. JI $=$ Qualitative JI measured with QUAL-JIS; $* p \leq .05, * * p \leq .01, * * * p \leq .001$, unmarked values signify

$p>$.05. Predictive values marked in bold, concurrent values in italics.

In the Romanian sample, qualitative JI at T1 predicted need for recovery at $\mathrm{T} 2$ with $\beta=.35$, $p<.001$, and qualitative JI at T2 predicted need for recovery at T3 with $\beta=.35, p<.001$. H7 was thus supported. We also checked if past qualitative JI predicted future need for recovery when future qualitative JI was considered. We did this by using two-step hierarchical linear regressions, with qualitative JI at different times added in separate steps. Results (see Table 7) showed that past qualitative JI significantly predicted future need for recovery, with $\beta_{T l}=.18, p<.001$ and $\beta_{T 2}=.31, p<.001$ in the Belgian sample, and $\beta_{T l}=.28, p<.001$ and $\beta$ $T 2=.39, p<.001$ in the Romanian sample, when taking future qualitative JI's contribution into account. 
Test-criterion incremental evidence. For measuring the incremental predictive aspect of validity, we performed two separate hierarchical linear regressions in the Belgian sample, one at T2 and one at T3. The dependent variable was the need for recovery, the independent variable in the first step of the regression was qualitative JI measured with the Hellgren et al. (1999) scale, and the independent variable in the second step of the regression was qualitative JI measured with QUAL-JIS. If, at each point in time, qualitative JI measured with QUAL-JIS would significantly relate to the need for recovery, after accounting for the statistical effect of qualitative JI measured with the Hellgren et al. (1999) scale, we would conclude that QUAL-JIS shows incremental predictive capacity, above and beyond the other scale. Results (see Table 8) provided support for H8.

Table 8

Incremental validity checks through hierarchical linear regression analyses, with the need for recovery as outcome

\begin{tabular}{|c|c|c|c|c|c|c|c|c|}
\hline Order & \multicolumn{4}{|c|}{ JI2 first } & \multicolumn{4}{|c|}{ JI1 first } \\
\hline Time & \multicolumn{2}{|c|}{$\mathrm{T} 2$} & \multicolumn{2}{|c|}{ T3 } & \multicolumn{2}{|c|}{$\mathrm{T} 2$} & \multicolumn{2}{|c|}{ T3 } \\
\hline Step & 1 & 2 & 1 & 2 & 1 & 2 & 1 & 2 \\
\hline$\beta \mathrm{JI} 1$ & & $.36 * * *$ & & $.37 * * *$ & $.35 * * *$ & $.36 * * *$ & $.36 * * *$ & $.37 * * *$ \\
\hline$\beta \mathrm{JI} 2$ & $.20 * * *$ & -.01 & $.22 * * *$ & -.01 & & -.01 & & -.01 \\
\hline Adjusted $R^{2}$ & .04 & .12 & .05 & .13 & .12 & .12 & .13 & .13 \\
\hline$\Delta R^{2}$ & $.04 * * *$ & $.08 * * *$ & $.05 * * *$ & $.09 * * *$ & $.12 * * *$ & $<.001$ & $.13 * * *$ & $<.001$ \\
\hline
\end{tabular}

Note. ${ }^{* * *} p \leq .001 ;$ unmarked values signify $p>.05 . N_{\mathrm{T} 2}=697 . N_{\mathrm{T} 3}=607$. Table contains standardized betas. JI1 = Qualitative JI measured with QUAL-JIS, JI2 = Qualitative JI measured with the scale from Hellgren et al. (1999).

In both cases, qualitative JI measured with the Hellgren et al. (1999) scale predicted need for recovery significantly in the first step of the regression. However, once the QUAL-JIS measurement of qualitative JI was added in the second step, the Hellgren et al. (1999) scale no longer met significance requirements $\left(\beta_{T 2}=-.008, p=.850 ; \beta_{T 3}=-.007, p=.888\right)$, while 
QUAL-JIS did $\left(\beta_{T 2}=.36, p<.001 ; \beta_{T 3}=.37, p<.001\right)$, with the QUAL-JIS measurement retaining the only significant results when predicting need for recovery.

\section{Discussion}

The goal of this article was to check the QUAL-JIS scale's psychometric properties, verifying its reliability and validity. Our findings indicate that QUAL-JIS may be a suitable measure for qualitative JI, the scale displaying reliability and validity evidence for assessing the degree to which employees anticipate unwanted changes regarding their valued job features. In our study we explained how a short and generic scale may be beneficial, and we showed how QUAL-JIS meets these criteria. We proposed that a selection of valued job features, as presented in qualitative JI measures on specific characteristics of work, may be a good fit for some specific organizational contexts and/or jobs and less so for others, depending on the constant evolution of jobs and organizations. We asserted that QUAL-JIS's ability to detect the presence of qualitative $\mathrm{JI}$ in a generic way would result in explaining additional variance in the outcome, compared to a scale measuring specific job features. We tested this final assertion by evaluating QUAL-JIS's increment in predicting the need for recovery, and results supported our hypothesis. Nevertheless, scales measuring specific characteristics of work have their own merits, perhaps the most important one being their ability to narrow-down the precise valued job features that may be perceived as being threatened; this is not possible with a generic scale.

Given the fact that our samples were not completely randomly selected (snowball procedure for Sample 1, and online survey for Sample 2), in addition to the presented results (i.e., Pearson correlations, linear regressions, and parameters calculated with the structural equation modelling maximum likelihood estimation), we used the bootstrapping options available in SPSS and Amos to calculate 95\% bias-corrected accelerated confidence intervals, based on 2000 bootstrap samples. We then verified that all reported estimates fell within the 
95\% CIs, and that none of the CIs included the value zero, where the reported estimates provided significant values.

To be able to accept QUAL-JIS as fit for usage, we needed to show that it is reliable. We determined reliability by calculating Cronbach's alpha coefficient, an indicator of the consistency of results across items. Results, ranging between 0.81 and 0.91 , supported our hypothesis.

The degree to which instruments cover all aspects related to the construct is one of the more essential concerns regarding existing qualitative JI scales. Given the extensive range of possible meaningful and valued job features, any scale which selects a subset of them may be prone to having a lower coverage of the construct, if applied in a different organizational setting than the one initially intended. The QUAL-JIS scale solves this problem by using context-independent items. We thus conclude that the scale shows a high level of evidence regarding its content matching the qualitative JI construct.

We found both convergent and discriminant evidence for qualitative JI scores measured with QUAL-JIS relating with other variables. The QUAL-JIS-measured qualitative JI correlated highly with, yet was distinct from quantitative JI, in line with convergent evidence requirements. The low corrected correlation between qualitative JI and the work engagement facet of dedication supports the hypothesized distinctiveness between the two constructs by providing discriminant evidence.

Regarding test-criterion relationships, we found both concurrent and predictive evidence: the QUAL-JIS-measured qualitative JI was related to the need for recovery, a known outcome for qualitative JI, both at the same time, and time-delayed. Results (see Table 7) indicate that while qualitative JI relates to the need for recovery when measured concurrently, it also predicts the future need for recovery, even when the future qualitative JI is taken into account. We also showed evidence regarding QUAL-JIS's scale incremental 
predicting accuracy compared to a widely used measure of qualitative JI (Hellgren et al., 1999), QUAL-JIS explaining additional variance in the outcome.

One important aspect for any scale validation is to check that the scale is invariant, meaning that it measures the same construct across context and time. In our case, we wanted to assess two invariance conditions: a) whether the QUAL-JIS scale is capturing the same construct in both countries, and b) if, when applied a number of times on the same group, the scale would be invariant. On both samples, the QUAL-JIS scale showed partial scalar invariance across the three measurement times, meaning that the respondents interpreted the questions in a similar manner every time. Regarding the cross-country invariance, our data indicated that the two translations of the QUAL-JIS scale were equivalent regarding factor structure, factor loadings, and half of the item intercepts, the scale showing partial scalar invariance. As such, the scale can be used in both languages and researchers may meaningfully compare observed means between the two countries, under certain conditions (Putnick \& Bornstein, 2016).

\section{Limitations and future research}

One limitation of the current study is that it relies exclusively on self-reported data, which may have increased the risk of socially desirable answers. However, since JI is a subjective perception, self-reports are the only way to measure it. Nevertheless, future research should be performed measuring qualitative JI with QUAL-JIS, in relationship with other-rated outcomes. To mitigate the risk of bias in the respondents' answers, we emphasized in the instructions the fact that participation was voluntary and that the study results would be confidential on an individual basis, as recommended by Podsakoff et al. (2003). Additionally, we collected variables in a lagged design, providing a temporal separation of measurement between predictor and outcome variables (Conway \& Lance, 2010). 
Second, although we surveyed different categories of participants, resulting in heterogeneous samples in both countries, the sampling methods (online survey in the Belgian sample and snowballing procedure in the Romanian one) could not provide nationally representative samples. Chain-referral sampling (i.e., "snowball" sampling), which we used in Sample 1, is a non-probabilistic sampling technique that has a number of advantages (in terms of ease of data collection) and a number of disadvantages in terms of possible biases. The main bias refers to variability in the collected sample, i.e., "community bias" - the participants who are selected in the beginning will have a strong influence over who else is nominated, and will usually nominate participants who are similar to them in terms of age, gender, occupation, interests, values etc. (Johnson, 2014; Parker et al., 2019). In our case, we tried to defend against these biases. The market research company that was commissioned began the snowball technique with a set of initial participants that were as diverse as possible. Then, we applied a variant of the sampling technique known as exponential discriminative snowball sampling, i.e., each participant was asked to indicate multiple referrals, but only one referral was recruited and followed from each participant; the interviewers were instructed to select in this way the most diverse possible sample. Furthermore, we removed self-employed respondents from our datasets because we considered that they could be dissimilar to regular employees regarding how they perceived qualitative JI. Self-employed workers might have a different understanding of uncertainty and control about unwanted changes compared to employees, being able to exercise more control about changes in their job situation, since they are usually the deciding factor. Despite the above, we point out that the final samples obtained in the two countries are reasonably well balanced on those demographic variables that were collected, and are not severely deviant from the proportions of those variables in the general population. For example, the mean age in the Romanian sample is 36 years, while the mean age for the adult population in Romania is 41 years; the gender split for our sample is 
$56 \%$ female to $44 \%$ male, and in the general population $51 \%$ female to $49 \%$ male; occupational diversity is also very high in our sample. For Belgium there is a slight overrepresentation of women in our sample, and an underrepresentation of blue-collar and low educated workers, while the other sample characteristics are very close to those of the country population. Nevertheless, future research on representative samples should be beneficial to further extend the generalizability of our findings.

Third, within our study we addressed only part of the WEIRD samples phenomenon (Western, Educated, people from Industrialized, Rich, and Democratic countries), a prevalent issue in psychological assessment (Pollet \& Saxton, 2019). We compared heterogeneous samples from a Western country (Belgium) and an Eastern European country (Romania), thus offering a certain degree of variability, given the different cultural and economic settings. However, we believe that future studies, replicating our results in different countries should be welcome. We recommend that already existing and future translations of the QUAL-JIS scale undergo a similar validation process, to provide the necessary assurance that they measure the same construct. Furthermore, even though the current study represents an indepth attempt to validate QUAL-JIS, it cannot offer an exhaustive assessment of validity evidence for every conceivable context. It is every research team's duty to assess aspects of reliability and validity, by examining the pre-existing evidence, as well as new relevant evidence for the study's specific context. Since not all validation standards can be met during the initial operational usages of a scale, it may be acceptable to delay meeting these standards. For example, some validation standards may call for analyses of data that are not yet available, or traditional quantitative analyses may not be feasible due to small sample sizes (American Educational Research Association et al., 2014). Nevertheless, as the body of knowledge grows, more evidence will become readily available for researchers. 
Fourth, scores obtained by measuring qualitative JI with QUAL-JIS at a certain time display high correlations with their quantitative JI counterparts, in both samples, indicating overlap in the measurement of the two constructs. At a first glance this would point to a potential validity issue, since the qualitative JI scale may tap into quantitative JI aspects as well. Still, we argue that this overlap between the two constructs is normal: losing the complete job means losing all the valued job features as well. The reverse, however, is not true: losing job features does not necessarily lead towards losing the job. To avoid confounding the two variables, we thus recommend that future studies which include one type of JI, measure the other type as well, to be able to get a complete picture regarding both aspects of JI and how they interact with other variables.

Finally, the greatest strength of the QUAL-JIS scale, its genericity, could also be considered, in certain cases, a limitation. Throughout the article we argued for a need to have a short, reliable and valid instrument for the detection of qualitative JI, and we showed that QUAL-JIS is such a measure. However, once a high level of qualitative JI is detected in an organization, the present scale is unable to narrow-down the root cause, since respondents may refer to very different issues when they agree with items of the QUAL-JIS scale. While this is intended and allows the scale to be used in any setting to detect qualitative JI, if an intervention is planned in the organization, a higher level of precision may be needed. In such a situation, we recommend that organizational psychologists continue, as a next step, with one of the following three options: either a) use a validated off-the-shelf scale listing the most prevalent reasons for JI (we listed and discussed all such current instruments in the Introduction section), b) construct a custom situation-tailored instrument, as has been done by Hellgren et al. (1999), or c) use qualitative methods, like interviews with the employees, to identify what affects them most. 


\section{Conclusion}

Throughout this article, we showed that the QUAL-JIS scale is reliable, with high internal consistency. We also provided evidence for the scale's validity, using cross-sectional and longitudinal data. We compared two translations of the scale, Dutch and Romanian, and concluded that the scale may be used in both languages. Our recommendation is to use the QUAL-JIS scale as a screening instrument for measuring qualitative JI in any context, especially if there is no validated instrument tailored for the specific valued job features in a particular organization, or when the research covers a multitude of diverse organizations. Notably, the QUAL-JIS measure may be a good choice in large scale scientific studies, where its briefness and genericity would offer large spectrum coverage at low item cost. 


\section{References}

American Educational Research Association, American Psychological Association, \& National Council on Measurement in Education, \& Joint Committee on Standards for Educational and Psychological Testing. (2014). Standards for educational and psychological testing. Washington, DC: AERA.

Ashford, S., Lee, C., \& Bobko, P. (1989). Content, causes, and consequences of job insecurity: A theory-based measure and substantive test. Academy of Management Journal, 32(4), 803-829. https://doi.org/10.5465/256569

Blotenberg, I., \& Richter, A. (2020). Validation of the QJIM: A measure of qualitative job insecurity. Work \& Stress, 34(4), 406-417. https://doi.org/10.1080/02678373.2020.1719553

Brondino, M., Bazzoli, A., Vander Elst, T., De Witte, H., \& Pasini, M. (2020). Validation and measurement invariance of the multidimensional qualitative job insecurity scale. Quality \& Quantity, 54(3), 925-942. https://doi.org/10.1007/s11135-020-00966-y

Burr, H., Berthelsen, H., Moncada, S., Nübling, M., Dupret, E., Demiral, Y., Oudyk, J., Kristensen, T. S., Llorens, C., Navarro, A., Lincke, H.-J., Bocéréan, C., Sahan, C., Smith, P., \& Pohrt, A. (2019). The third version of the Copenhagen Psychosocial Questionnaire. Safety and Health at Work, 10, 482-503.

https://doi.org/10.1016/j.shaw.2019.10.002

Chen, F. F. (2007). Sensitivity of Goodness of Fit Indexes to Lack of Measurement Invariance, Structural Equation Modeling, 14(3), 464-504. https://doi.org/10.1080/10705510701301834

Cheung, G.W., \& Rensvold, R. B. (2002). Evaluating goodness-of-fit indexes for testing measurement invariance. Structural Equation Modeling, 9(2), 233-255. https://doi.org/10.1207/S15328007SEM0902_5 
Chirumbolo, A., \& Areni, A. (2010). Job insecurity influence on job performance and mental health: Testing the moderating effect of the need for closure. Economic and Industrial Democracy, 31(2), 195-214. https://doi.org/10.1177/0143831X09358368

Conway, J. M., \& Lance, C. E. (2010). What Reviewers Should Expect from Authors Regarding Common Method Bias in Organizational Research. Journal of Business and Psychology, 25, 325-334. https://doi.org/10.1007/s10869-010-9181-6

Cohen, J. (1988). Statistical power analysis for the behavioral sciences (2nd ed.). Hillsdale, NJ: Lawrence Erlbaum Associates.

De Witte, H. (2000). Arbeidsethos en jobonzekerheid: Meting en gevolgen voor welzijn, tevredenheid en inzet op het werk [Work ethic and job insecurity: Assessment and consequences for well-being, satisfaction and performance at work]. In R. Bouwen, K. De Witte, H. De Witte \& T. Taillieu (Eds.), Van groep naar gemeenschap [From group to community]. Liber Amicorum Prof. Dr. Leo Lagrou (pp. 325-350). Leuven: Garant.

De Witte, H., De Cuyper, N., Handaja, Y., Sverke, M., Näswall, K., \& Hellgren, J. (2010). Associations between quantitative and qualitative job insecurity and well-being. International Studies of Management \& Organization, 40(1), 40-56. https://doi.org/10.2753/IMO0020-8825400103

De Witte, H., Pienaar, J., \& De Cuyper, N. (2016). Review of 30 years of longitudinal studies on the association between job insecurity and health and well-being: Is there causal evidence? Australian Psychologist, 51(1), 18-31. https://doi.org/10.1111/ap.12176

Fischmann, G., De Witte, H., Sulea, C., \& Iliescu, D. (2018). Qualitative job insecurity and in-role performance: a bidirectional longitudinal relationship?, European Journal of Work and Organizational Psychology, 27(5), 603-615. https://doi.org/10.1080/1359432X.2018.1504769 
Fischmann, G., De Witte, H., Sulea, C., Vander Elst, T., De Cuyper, N., \& Iliescu, D. (2021). Supplementary materials for: Validation of a short and generic qualitative job insecurity scale (QUAL-JIS). http://dx.doi.org/10.23668/psycharchives.4881

Fischmann, G., Sulea, C., Kovacs, P., Iliescu, D., \& De Witte, H. (2015). Qualitative and quantitative job insecurity: Relations with nine types of performance. Psihologia Resurselor Umane, 13(2), 152-164.

Gallie, D., Felstead, A., Green, F., \& Inanc, H. (2017). The hidden face of job insecurity. Work, employment and society, 31(1) 36-53. https://doi.org/10.1177/0950017015624399

Garrido Vásquez, M. E., Truyen, C., \& Otto, K. (2017). A new hope through positive psychology: High-quality connections and psychological safety as protective barrier against job insecurity perceptions. Latinoamerican Journal of Positive Psychology, $3(3), 42-61$.

Greenhalgh, L., \& Rosenblatt, Z. (1984). Job insecurity: towards conceptual clarity. Academy of Management Review, 9, 438-448. https://doi.org/10.2307/258284

Hellgren, J., Sverke, M., \& Isaksson, K. (1999). A two-dimensional approach to job insecurity: Consequences for employee attitudes and well-being. European Journal of Work and Organization Psychology, 8, 179-195.

https://doi.org/10.1080/135943299398311

Hofstede, G. (2011). Dimensionalizing Cultures: The Hofstede Model in Context. Online Readings in Psychology and Culture, 2(1), 1-26. https://doi.org/10.9707/23070919.1014

Hu, L.-t., \& Bentler P. M. (1999). Cutoff criteria for fit indexes in covariance structure analysis: Conventional criteria versus new alternatives. Structural Equation 
Modeling: A Multidisciplinary Journal, 6(1), 1-55.

https://doi.org/10.1080/10705519909540118

Hulin C., Netemeyer, R., \& Cudeck, R. (2001). Can a Reliability Coefficient Be Too High? Journal of consumer psychology, 10(1\&2), 55-58. https://doi.org/10.1207/S15327663JCP1001\&2_05

Iliescu, D., Macsinga, I., Sulea, C., Fischmann, G., Vander Elst, T., \& De Witte, H. (2017). The five-factor traits as moderators between job insecurity and health: A vulnerability-stress perspective. Career Development International, 22(4), pp. 399418. https://doi.org/10.1108/CDI-08-2016-0146

Johnson, T. P. (2014). Snowball Sampling: Introduction. In N. Balakrishnan, T. Colton, B. Everitt, W. Piegorsch, F. Ruggeri \& J. L. Teugels (Eds.), Wiley StatsRef: Statistics Reference Online. https://doi.org/10.1002/9781118445112.stat05720

Kalyal, H. J., \& Sverke, M. (2010). The role of trust in decision makers as a moderator in the relationship between qualitative job insecurity and affective commitment to change. Pakistan Journal of Psychological Research, 25(1), 65-78.

Låstad, L., Berntson, E., Näswall, K., Lindfors, P., \& Sverke, M. (2015). Measuring quantitative and qualitative aspects of the job insecurity climate. Career Development International, 20(3), 202-217. https://doi.org/10.1108/CDI-03-2014-0047

Lazarus, R. S., \& Folkman, S. (1984). Stress, appraisal, and coping. New York: Springer.

Lee, C., Bobko, P., Ashford, S., Chen, Z. X., \& Ren, X. (2008). Cross-cultural development of an abridged job insecurity measure. Journal of Organizational Behavior, 29(3), 373-390. https://doi.org/10.1002/job.513

Lee, C., Huang, G.-H., \& Ashford, S. J. (2018). Job Insecurity and the Changing Workplace: Recent Developments and the Future Trends in Job Insecurity Research. Annual 
Review of Organizational Psychology and Organizational Behavior, 5(1), 335-359. https://doi.org/10.1146/annurev-orgpsych-032117-104651

Niesen, W., Van Hootegem, A., Handaja, Y., Battistelli, A., \& De Witte, H. (2018).

Quantitative and qualitative job insecurity and idea generation: The mediating role of psychological contract breach. Scandinavian Journal of Work and Organizational Psychology, 3(1), 1-14. https://doi.org/10.16993/sjwop.36

Nikolova, I., van Dam, K., Van Ruysseveldt, J., \& De Witte, H. (2019). Feeling Weary? Feeling Insecure? Are All Workplace Changes Bad News?. International journal of environmental research and public health, 16(10), 1842. https://doi.org/10.3390/ijerph16101842

Notelaers, G., De Witte, H., Van Veldhoven, M., \& Vermunt, J. K. (2007). Construction and validation of the Short Inventory to Monitor Psychosocial Hazards. Arbeidsgezondheidszorg en Ergonomie, 44(1), 11-17.

O'Neill, P., \& Sevastos, P. (2013). The development and validation of a new multidimensional Job Insecurity Measure (JIM): An inductive methodology. Journal of Occupational Health Psychology, 18(3), 338-349. https://doi.org/10.1037/a0033114

Parker, C., Scott, S., \& Geddes, A. (2019). Snowball Sampling. In P. Atkinson, S. Delamont, A. Cernat, J. W. Sakshaug \& R. A. Williams (Eds.), Sage Research Methods Foundations (pp. 2-8). SAGE. http://dx.doi.org/10.4135/9781526421036831710

Podsakoff, P. M., MacKenzie, S. B., Lee, J.-Y., \& Podsakoff, N. P. (2003). Common method biases in behavioral research: A critical review of the literature and recommended remedies. Journal of Applied Psychology, 88, 879-903. https://doi.org/10.1037/00219010.88 .5 .879 
Pollet, T.V., \& Saxton, T.K. (2019). How Diverse Are the Samples Used in the Journals 'Evolution \& Human Behavior' and 'Evolutionary Psychology'? Evolutionary Psychological Science, 5, 357-368. https://doi.org/10.1007/s40806-019-00192-2

Putnick, D. L., \& Bornstein, M. H. (2016). Measurement invariance conventions and reporting: The state of the art and future directions for psychological research. Developmental Review, 41, 71-90. https://doi.org/10.1016/j.dr.2016.06.004

Roll, L. C., Siu, O.-1., Li, S. Y. W. and De Witte, H. (2015). Job insecurity: cross-cultural comparison between Germany and China, Journal of Organizational Effectiveness: People and Performance, 2(1), pp. 36-54. https://doi.org/10.1108/JOEPP-01-20150002

Roll, L. C., Siu, O.-1., Li, S. Y. W., \& De Witte, H. (2019). Human Error: The Impact of Job Insecurity on Attention-Related Cognitive Errors and Error Detection. International Journal of Environmental Research and Public Health, 16(13), 2427. https://doi.org/10.3390/ijerph16132427

Schaufeli, W. B., \& Bakker, A. B. (2010). The conceptualization and measurement of work engagement. In A.B. Bakker \& M.P. Leiter (Eds.), Work engagement: A handbook of essential theory and research (pp. 10-24). New York: Psychology Press.

Schaufeli, W. B., Salanova, M., González-Romá, V. \& Bakker, A. B (2002). The measurement of engagement and burnout: A two sample confirmatory factor analytic approach. Journal of Happiness Studies, 3, 71-92.

https://doi.org/10.1023/A:1015630930326

Schmitt, N., \& Kuljanin, G. (2008). Measurement invariance: Review of practice and implications. Human Resource Management Review, 18, 210-222. https://doi.org/10.1016/j.hrmr.2008.03.003 
Shoss, M. K. (2017). Job insecurity: An integrative review and agenda for future research. Journal of Management, 43(6), 1911-1939. https://doi.org/10.1177/0149206317691574

Sverke, M., Hellgren, J., \& Näswall, K. (2002). No security: A meta-analysis and review of job insecurity and its consequences. Journal of Occupational Health Psychology, 7, 242-264. https://doi.org/10.1037/1076-8998.7.3.242

Sverke, M., Låstad, L., Hellgren, J., Richter, A., \& Näswall, K. (2019). A Meta-Analysis of Job Insecurity and Employee Performance: Testing Temporal Aspects, Rating Source, Welfare Regime, and Union Density as Moderators. International Journal of Environmental Research and Public Health, 16(14), 2536. https://doi.org/10.3390/ijerph16142536

Tavakol, M., \& Dennick, R. (2011). Making sense of Cronbach's alpha. International Journal of Medical Education, 2, 53-55. https://doi.org/10.5116/ijme.4dfb.8dfd Urbanaviciute, I., Lazauskaite-Zabielske, J., Vander Elst, T., \& De Witte, H. (2018). Qualitative job insecurity and turnover intention: The mediating role of basic psychological needs in public and private sectors. Career Development International, 23(3), 274-290. https://doi.org/10.1108/CDI-07-2017-0117

Urbanaviciute, I., Roll, L. C., Tomas, J., \& De Witte, H. (2020). Proactive strategies for countering the detrimental outcomes of qualitative job insecurity in academia. Stress \& Health, 37(3), 557-571. https://doi.org/10.1002/smi.3023

Van den Broeck, A., Sulea, C., Vander Elst, T., Fischmann, G., Iliescu, D., \& De Witte, H. (2014). The mediating role of psychological needs in the relation between qualitative job insecurity and counterproductive work behavior. Career Development International, 19(5), pp. 526-547. https://doi.org/10.1108/CDI-05-2013-0063 
Van den Broeck, A., Van Hootegem, A., Vander Elst, T., \& De Witte, H. (2019). Do selfenhancing and affiliative humor buffer for the negative associations of quantitative and qualitative job insecurity? The Spanish Journal of Psychology, 22. https://doi.org/10.1017/sjp.2019.7

Van Hootegem, A., \& De Witte, H. (2019). Qualitative Job Insecurity and Informal Learning: A Longitudinal Test of Occupational Self-Efficacy and Psychological Contract Breach as Mediators. International Journal of Environmental Research and Public Health, 16(10), 1-24. https://doi.org/10.3390/ijerph16101847

Vander Elst, T., De Witte, H., \& De Cuyper, N. (2014). The Job Insecurity Scale: A psychometric evaluation across six European countries. European Journal of Work and Organizational Psychology, 23(3), 364-380. https://doi.org/10.1080/1359432X.2012.745989

Virga, D. (2015). Job insecurity and job satisfaction: The mediating effect of psychological capital. Psihologia Resurselor Umane, 13, 206-216. 